\title{
Mayor histocompatibility complex class II (HLA-DR) is associated with morphea and systemic sclerosis patients
}

\author{
Natalia Rebollo-Domínguez ${ }^{1}$, María-Elisa Vega-Memije², Pablo Villaseñor-Ovies ${ }^{3}$, Maricela \\ García-Lechuga $^{4}$, Julio Granados ${ }^{4 *}$, Lucia Rangel-Gamboa ${ }^{5 *}$ \\ ${ }^{1}$ Autonomous University of Baja California, Tijuana, Mexico; \\ ${ }^{2}$ Department of Dermatopathology, General Hospital "Dr. Manuel Gea González", CDMX, Mexico; \\ ${ }^{3}$ General Hospital of Tijuana, Autonomous University of Baja California, Tijuana, Mexico; \\ ${ }^{4}$ Department of Transplants and Immunogenetic, Nacional Institute of Medical Sciences and Nutrition, "Salvador Zubirán", CDMX, México; \\ ${ }^{5}$ Department of Ecology \& Pathogenic Agents, General Hospital "Dr. Manuel Gea González", CDMX, México.
}

\begin{abstract}
Morphea is a disorder limited to the skin, characterized by a stable oval plaque with a glossy plane surface that feels indurated on palpation. In contrast, systemic sclerosis is additionally characterized by disseminate cutaneous engrossment, sclerodactyly, the presence of Raynaud's phenomenon, and internal organ involvement. Human leukocyte antigen (HLA)-DR4 class II alleles are associated with morphea in Caucasians, whereas, HLADR4 presents as high frequency in Amerindians, besides it was associated with autoimmune disease. The aim of this study was to determine HLA-DR alleles in Mexican patients with morphea. This study recruited 24 morphea patients, whose HLA alleles frequencies were compared with HLA alleles frequencies presented in 22 systemic sclerosis patients and 99 ethnically matched healthy controls. The HLA-DR $\beta 1$ locus was genotyped based on the hybridization technique. HLA-DR4 and DR8 frequencies showed increases in morphea patients compared with healthy controls, whereas HLA-DR4 exhibited a statistical association with morphea when allele frequencies were compared with systemic sclerosis patients. Thus, HLA-DR $\beta 1$ associations varied in morphea and systemic sclerosis, suggesting the participation of different immunological molecular mechanisms.
\end{abstract}

Keywords: morphea, HLA class II , HLA-DR4, HLA-DR5, systemic sclerosis, Mexican mestizo

\section{INTRODUCTION}

Morphoea or localized scleroderma (LS) is a disorder limited to the skin. Clinical presentation is

\footnotetext{
*Correspondence to: Lucia Rangel-Gamboa, PhD. Department of Ecology \& Pathogenic Agents, General Hospital "Dr. Manuel Gea González",Calzada de Tlalpan 4800, Sección XVI, Tlalpan, CDMX, México. C.P 14080; TEL: 00525540003000 extensions 6100, E-mail: draluciarage1@yahoo.com.mx. Julio Granados, PhD. Department of Transplants and Immunogenetic, Nacional Instituteof Medical Sciences and Nutrition, "Salvador Zubirán", 7a Cerrada de Fray Pedro de Gante
}

characterized by a stable oval plaque with a glossy plane surface, often with a purple or brown edge that feels indurated on palpation. Patients with morphea frequently have systemic symptoms, for instance malaise, fatigue, arthralgia and myalgia, in addition they are more likely to present positive autoantibodies in serology ${ }^{[1]}$. Antihistone antibody (AHA) and single-

\footnotetext{
50, Tlalpan Sección XVI, CDMX, México. C.P 14080. TEL: 005255 54850080, E-mail: julgrate@yahoo.com.

Conflict of interest: The authors declare no conflict of interest. We also confirm that none of the authors have any professional or financial relationship with the individuals who were recommended to review the manuscript.
} 
stranded DNA antibody (ssDNA ab) are associated with functional limitations, while antinuclear antibody (ANA) and ssDNA ab are associated with extensive involvement of the body surface area. Nevertheless, autoantibody testing is considered of limited clinical significance except in patients with linear morphea, where ANA, AHA and ssDNA may be potential markers of the disease's severity and prognosis ${ }^{[2]}$. Morphea requires histopathological confirmation in clinical diagnosis, and cutaneous biopsy exhibits inflammation at early stages. The complemental immunohistochemical analyses display a predominance of $\mathrm{CD}_{4}^{+}$lymphocytes. While in the latter stages, significant fibrosis of dermis with the occurrence of collagen deposition dominates ${ }^{[3,4]}$. Previously, studies attempted to explain morphea as an immunological response to the Borrelia burgdorferi infection, but actual evidences consider this relationship unlikely ${ }^{[5]}$. In contrast, the clinical presentation of systemic sclerosis (also known as scleroderma or SSc) is characterized by disseminate cutaneous engrossment, sclerodactyly, the presence of Raynaud's phenomenon (95\%), nailfold capillary changes and internal organ involvement (heart, lung, kidneys and gastrointestinal system ${ }^{[6]}$. The autoantibodies found more frequently are anti-centromere (ACA, 15\% 43\%), anti-topoisomerase I (anti-Scl70, $21 \% \sim 34 \%$ ), anti-RNA polymerase II and antiRNP (both in $5 \%$ of patients) ${ }^{[7]}$. Still, the differences in clinical presentation both conditions of uncertain etiology were considered immunologically mediated and related ${ }^{[8]}$. Recently, an epigenetic approach in systemic sclerosis research showed an overexpression of CD40L, CD11 and CD70, associated with global reduced DNA methylation, whereas the Foxp3 promoter region gains a hypermethylation mark that limits the proliferation and functional activity of Treg cells ${ }^{[9]}$. Essentially, it is considered that genetic contribution factors for SSc predisposition belong predominantly to the immune response $\operatorname{loc}^{[10]}$, thus in systemic sclerosis patients, specific HLA alleles are associated and related to different ethnicities ${ }^{[11-15]}$. In contrast, no morpheaepigenetic information is available, nevertheless, in the United States HLA-DR4 allele was found related to morphea. Still, according to the best of our knowledge, in Latin-American HLA class II associations have not been established in morphea patients. This is important because the genetic background of Amerindians differs from the Caucasian population, and has evolved geographically by natural selection (especially during the last five centuries) owing to survival against new infectious agents, which were introduced during the colonization process ${ }^{[16]}$. Thus, the aim of this study was to determine HLA-DR alleles in Mexican mestizo patients with morphea and compare them with HLADR allele frequencies from Mexican mestizo systemic sclerosis patients and healthy controls.

\section{MATERIAL AND METHODS}

\section{Subjects}

This observational, epidemiological study was performed during a three years period. During this time a total of 24 patients were recruited with a clinical diagnosis of morphea confirmed by histopathology, who presented at the Dermatology Department in General Hospital Dr. Manuel Gea Gonzalez, in Mexico City. The median age at diagnosis was 32.1(8-72) years and there were $21(87.5 \%)$ females and $3(12.5 \%)$ males. DNA was obtained only from 18 morphea patients. Gene frequencies of HLA alleles were compared with those presenting 22 systemic sclerosis patients diagnosed at the Nacional Instituteof Medical Sciences and Nutrition, "Salvador Zubirán", and 99 ethnically matched healthy controls. Ethnically, the patients and controls were classified as mestizos, who are defined as individuals born in Mexico, with Mexican ancestors dating to at least the third generation and with Spanish-derived last names. Mestizos are the result of five centuries of admixture between Amerindians (Asian origin), Spaniards and Africans, and represent most of the Mexican population ${ }^{[17,18]}$. The study protocol was revised and approved by the Hospital Ethics Committee. The ideal number of subjects to be included was defined according the mathematical formula for calculations of two proportions; resulting in 21 patients. Written informed consent was obtained from all subjects before their admission in the study. All procedures were in accordance with the ethical standards of the appropriate committee on human experimentation and Helsinki Declaration.

\section{HLA-DRß1 typing}

Genomic DNA from all subjects included in this study was purified from peripheral blood leukocytes, according to the method described by Miller ${ }^{[19]}$. Blood was collected from a single peripheral venipuncture, consistent with the current human rights guidelines, and all the procedures were approved by the Internal Review Boards of the institution. The HLA-DR $\beta 1$ locus was genotyped based on the hybridization of labelled single-stranded polymerase chain reaction products to sequence-specific oligonucleotides, using the Life Codes HLA-DR $\beta 1$ Typing Kit for use with Luminex (Gen-Probe Transplant Diagnostics, Inc., Stamford, CT, USA), following the manufacturer's recommendations. Data were analyzed using 
the quicktype for Lifecodes version 3.0 software to determine the HLA alleles. Allele frequencies were calculated by direct counting.

\section{Statistical analysis}

The allele frequencies were calculated by direct counting, and the differences in the distribution of the alleles between patients and controls were analyzed using the odds ratios, 95\% confidence interval and significance level. Statistical analyses were performed using the EPIINFO software, version 5.0 (USD incorporated 1990, Stone Mountain, GA, USA). Statistically significant $P$ values $(\leqslant 0.05$ ) were corrected by Mantel Haenszel method, considering the number of alleles observed $(\mathrm{pC})^{[20]}$.

\section{RESULTS}

Demographic and clinical features of the morphea patients are summarized in Table 1. The data showed the disease predominance in middle age females, who exhibited plaque and linear morphea as prevailed form of presentation (Fig.1); 36\% of lesions were observed in the trunk, the rest were presented, in equal proportions, in the high and lower extremities. The clini-

cal diagnosis was corroborated by histopathological study in all cases (Fig.2). In general, this epidemiological information is in accordance with previous publications ${ }^{[21,22]}$. In relation to HLA frequencies, the results showed that $\mathrm{DR} 4$ increased $(\mathrm{pC}=0.05)$ with an absence of DR5 in morphea patients compared with healthy controls, specially allele DR*04:11 with statistical significance ( $\mathrm{pC}=0.01$, Table 2). Subsequently, genetic frequencies of HLA class II alleles in morphea patients were compared to data from patients with systemic sclerosis: in this case HLA-DR4 exhibited statistical association with morphea, whereas HLA-DR5 presented an association with systemic sclerosis (Table 3, pC $=0.009$ and 0.005 , correspondingly).

Table 1 Baseline of patients with RBC autoantibodies

\begin{tabular}{lccc}
\hline Morphea subtype & {$[(\mathrm{n}) \%]$} & $\begin{array}{c}\text { Age } \\
[\mathrm{y}, \text { mean(range })]\end{array}$ & $\begin{array}{c}\text { Years of evolution } \\
{[\mathrm{y}, \text { mean(range })}\end{array}$ \\
\hline Plaque & $11(45.83)$ & $26.70(9-72)$ & $8.00(2-18)$ \\
Linear & $6(25.00)$ & $17.50(8-41)$ & $7.80(3-8)$ \\
En coup de sabre & $3(12.50)$ & $43.50(16-69)$ & $10.43(7-12)$ \\
Generalized & $3(12.50)$ & $34.60(12-37)$ & $8.10(3-16)$ \\
Deep morphea & $1(4.16)$ & 37 & 2 \\
\hline
\end{tabular}
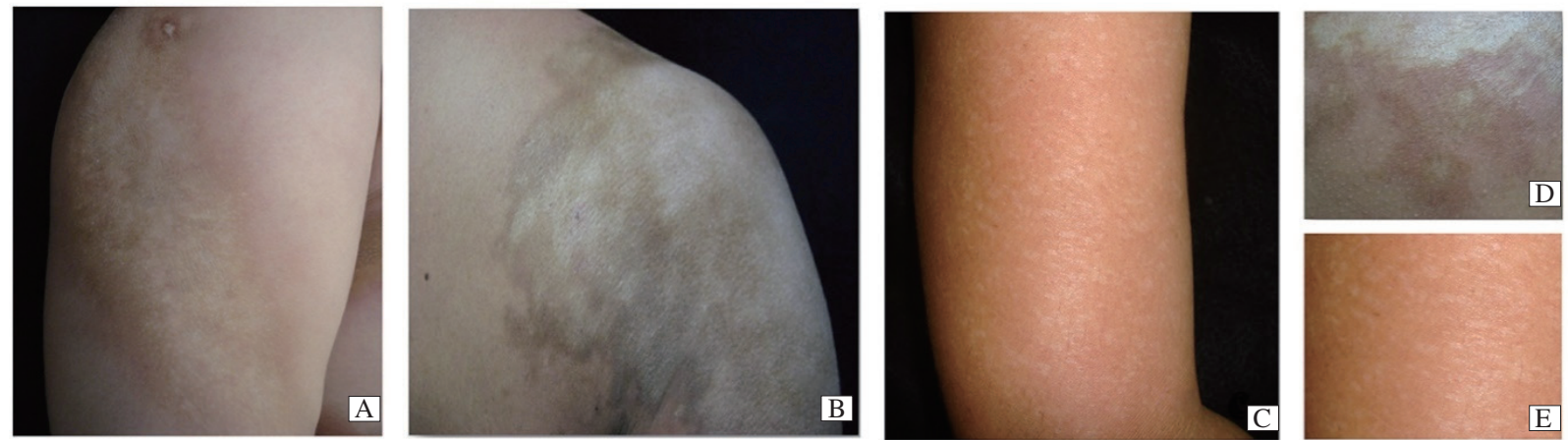

Fig. 1 Morphea clinical presentation. A: linear; B: plaque; C: punctuate; D: approach of B; E: approach of C.

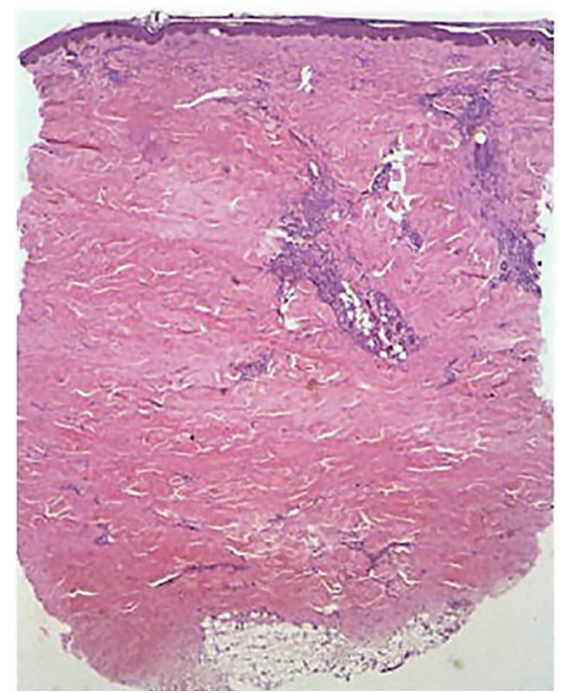

Fig. 2 Histopathological image.

\section{DISCUSSION}

In the population of the United States of America, Jacobe et al. reported the association of HLA-DR4 in morphea patients ${ }^{[23]}$. In the present study, HLADR4 (especially DR*04:11) also presented higher allele frequency values in morphea patients, compared with healthy controls, with a statistical significance $(P=0.01)$. This association is important considering the high frequency of DR4 in Mexican Mestizo population $^{[23]}$, as a consequence of genetic bottleneck events produced during initial human migration to America and in the colonial period, associated with human infections and ethnic violence ${ }^{[24-26]}$. Moreover, when HLA-DR allele frequencies from morphea patients were compared with those of systemic sclerosis patients, HLA-DR4 exhibited an association with 
Table 2 HLA-class II alleles in patients with morphea and healthy controls

\begin{tabular}{|c|c|c|c|c|c|c|c|}
\hline \multirow{3}{*}{$\begin{array}{l}\text { Allele } \\
\text { DR4 }\end{array}$} & \multicolumn{2}{|c|}{ Patients(alleles $n=36$ ) } & \multicolumn{2}{|c|}{ Healthy controls (alleles $n=198$ ) } & \multirow{2}{*}{$\mathrm{pC}$} & \multirow{2}{*}{ OR } & \multirow{2}{*}{$95 \% \mathrm{CI}$} \\
\hline & & g.f & & & & & \\
\hline & 14 & 0.380 & 47 & 0.237 & 0.05 & 2.04 & $0.91-4.50$ \\
\hline $\mathrm{DR} * 04: 07$ & 6 & 0.166 & 21 & 0.106 & 0.29 & 1.68 & $0.62-4.50$ \\
\hline DR*04:04 & 2 & 0.055 & 9 & 0.045 & 0.79 & 1.30 & $0.20-6.20$ \\
\hline $\mathrm{DR} * 04: 03$ & 3 & 0.083 & 4 & 0.041 & 0.13 & 4.40 & $0.90-20.60$ \\
\hline $\mathrm{DR} * 04: 11$ & 3 & 0.083 & 3 & 0.015 & 0.01 & 5.90 & $1.10-30.50$ \\
\hline $\mathrm{DR} * 04: 02$ & NP & NP & 2 & 0.010 & & & \\
\hline Others & NP & NP & 8 & 0.040 & & & \\
\hline DR8 & 10 & 0.270 & 33 & 0.166 & 0.11 & 1.92 & $0.84-4.36$ \\
\hline DR*08:02 & 10 & 0.277 & 30 & 0.151 & 0.07 & 2.11 & $0.92-4.83$ \\
\hline DR*08:04 & NP & NP & 3 & 0.015 & & & \\
\hline DR6 & 3 & 0.083 & 31 & 0.156 & 0.25 & 0.49 & $0.14-1.69$ \\
\hline DR*13:01 & 2 & 0.055 & 4 & 0.020 & & & \\
\hline DR*13:02 & $\mathrm{NP}$ & NP & 4 & 0.020 & & & \\
\hline DR*14:02 & 1 & 0.027 & 7 & 0.035 & & & \\
\hline DR*14:01 & NP & NP & 6 & 0.030 & & & \\
\hline Others & $\mathrm{NP}$ & NP & 10 & 0.050 & & & \\
\hline DR2 & 3 & 0.083 & 18 & 0.090 & 0.88 & 0.90 & $0.25-3.20$ \\
\hline DR*15:01 & 2 & 0.055 & 9 & 0.045 & & & \\
\hline DR*15:02 & 1 & 0.027 & 3 & 0.015 & & & \\
\hline DR*16:02 & NP & $\mathrm{NP}$ & 3 & 0.015 & & & \\
\hline Others & NP & NP & 3 & 0.015 & & & \\
\hline \multicolumn{8}{|l|}{ DR7 } \\
\hline $\mathrm{DR} * 07: 01$ & 2 & 0.055 & 22 & 0.111 & & & \\
\hline DR5 & 0 & 0 & 22 & 0.110 & 0.10 & 0.28 & $0.02-1.66$ \\
\hline DR*11:01 & $\mathrm{NP}$ & NP & 12 & 0.060 & & & \\
\hline DR*11:04 & NP & NP & 4 & 0.020 & & & \\
\hline DR*12:01 & NP & NP & 2 & 0.010 & & & \\
\hline Others & $\mathrm{NP}$ & NP & 4 & 0.020 & & & \\
\hline Others & 4 & 0.129 & 25 & 0.126 & - & - & - \\
\hline
\end{tabular}

g.f: genetic frequency, OR: odds ratio, CI: confidence interval, pC: $P$-value, Corrected by Mantel Haenszel method.

morphea patients, and HLA-DR5 with systemic sclerosis patients ${ }^{[27,28]}$. Congruently, morphea may be present in association with autoimmune diseases, such as rheumatoid arthritis ${ }^{[29,30]}$ which was previously associated with HLA-DR $4^{[31,32]}$. Besides, other skin autoimmune mediated diseases, such as actinic prurigo and pemphigus were associated with HLA-DR4 in the Mexican Mestizo population ${ }^{[33-35]}$. In agreement with these data, several authors described an elevation in HLA-DR cellular expression in morphea biopsies, especially presented in factor $\mathrm{VIII} \mathrm{a}^{+}$dendritic cells (DDCs) and lymphocytes ${ }^{[4,36,37]}$. Thus a plausible model of morphea pathogenesis comprises a triggering event in a genetically susceptible individual, that fallouts in a cascade of innate and adaptive immunoinflammation with profibrotic rejoinder, involving probable epidermal signaling and mesenchymal mediators $^{[8]}$. Interestingly, the morphea-associated alleles are different from those found in systemic sclerosis, suggesting that morphea is an immunogenetically distinct entity. Therefore, the study concluded that even if the two disorders share fibrosis, different molecular immunologic mechanisms are involved, which has been supported by other authors in recent publica- tions who used different approaches to understand the pathologic phenomena ${ }^{[38-40]}$.

\section{Acknowledgements}

This study was financial supported by Sub-direction of Research and Dermatology Department of General Hospital Dr. Manuel Gea González; and Department of Transplants and Immunogenetic, Nacional Institute of Medical Sciences and Nutrition, "Salvador Zubirán". We sincerely thank all patients for participating in this study.

\section{References}

[1] Dharamsi JW, Victor S, Aguwa N, et al. Morphea in adults and children Cohort III Nested case-control study- The clinical significance of autoantibodies in morphea. JAMA Dermatol, 2013,149(10):1159-65.

[2] Chiu Y. Evaluating the clinical utility of autoantibodies in Morphea. JAMA Dermatol, 2013,149(10):1166.

[3] Wortsman X, Ma L, Chung WK, et al. Evaluation of the CAVl gene in clinically, sonographically and histologically proven morphea patients. Exp Dermatol, 2015,24(9):713-20.

[4] Gilmour TK, Wilkinson B, Breit SN, et al. Analysis of dendritic cell populations using a revised histo- 
Table 3 HLA class II alleles in morphea and systemic sclerosis patients

\begin{tabular}{|c|c|c|c|c|c|c|c|}
\hline \multirow[t]{2}{*}{ Allele } & \multicolumn{2}{|c|}{$\begin{array}{l}\text { Morphea patients } \\
\text { (alleles } n=36)\end{array}$} & \multicolumn{2}{|c|}{$\begin{array}{c}\text { Systemic sclerosis patients } \\
\text { (alleles } n=44)\end{array}$} & \multirow[t]{2}{*}{$\mathrm{pC}$} & \multirow[t]{2}{*}{ OR } & \multirow[t]{2}{*}{$95 \% \mathrm{CI}$} \\
\hline & $n$ & g.f & $n$ & g.f & & & \\
\hline DR4 & 14 & 0.380 & 6 & 0.136 & 0.009 & 4.14 & \\
\hline $\mathrm{DR} * 04: 07$ & 6 & 0.16 & 3 & 0.06 & 0.16 & 2.73 & $0.63-11.81$ \\
\hline DR*04:04 & 2 & 0.05 & 1 & 0.02 & 0.44 & 2.52 & $0.22-29.08$ \\
\hline DR*04:03 & 3 & 0.08 & 1 & 0.02 & 0.21 & 3.90 & $0.38-39.31$ \\
\hline $\mathrm{DR} * 04: 11$ & 3 & 0.08 & 1 & 0.02 & 0.21 & 3.90 & $0.38-39.31$ \\
\hline DR*04:02 & NP & NP & NP & NP & - & - & - \\
\hline \multicolumn{8}{|l|}{ DR8 } \\
\hline $\mathrm{DR} * 08: 02$ & 10 & 0.27 & 9 & 0.20 & 0.44 & 1.49 & $0.53-4.20$ \\
\hline DR*08:04 & NP & NP & NP & NP & - & - & - \\
\hline \multicolumn{8}{|l|}{ DR6 } \\
\hline $\mathrm{DR} * 13: 01$ & 2 & 0.05 & NP & NP & - & - & - \\
\hline $\mathrm{DR}^{*} 13: 02$ & NP & NP & NP & NP & & & \\
\hline DR*14:02 & 1 & 0.02 & NP & NP & & & \\
\hline $\mathrm{DR}^{*} 14: 01$ & NP & $\mathrm{NP}$ & NP & NP & & & \\
\hline \multicolumn{8}{|l|}{ DR2 } \\
\hline DR*15:01 & 2 & 0.05 & 1 & 0.02 & 0.44 & 2.52 & $0.22-29.08$ \\
\hline DR*15:02 & 1 & 0.02 & NP & NP & & & \\
\hline $\mathrm{DR}^{*} 16: 02$ & NP & NP & 1 & 0.02 & & & \\
\hline \multicolumn{8}{|l|}{ DR7 } \\
\hline $\mathrm{DR}^{*} 07: 01$ & 2 & 0.05 & 4 & 0.09 & 0.55 & 0.58 & $0.10-3.41$ \\
\hline DR5 & 0 & 0.00 & 10 & 0.227 & 0.005 & 0.09 & $0.00-0.77$ \\
\hline DR*11:01 & NP & $\mathrm{NP}$ & 2 & 0.04 & 0.41 & 0.39 & $0.03-3.92$ \\
\hline DR*11:04 & NP & NP & 7 & 0.15 & 0.03 & 0.12 & $0.01-1.08$ \\
\hline DR*11:02 & NP & NP & 1 & 0.02 & 0.69 & 0.60 & $0.05-6.89$ \\
\hline $\mathrm{DR}^{*} 12: 01$ & NP & NP & NP & NP & - & - & - \\
\hline Others & 4 & 0.11 & 13 & 0.29 & - & - & - \\
\hline
\end{tabular}

g.f = genetic frequency, OR: odds ratio, CI: confidence interval, pC: $P$-value, Corrected by Mantel Haenszel method.

logical staging of morphoeaMorphea. Br J Dermatol, 2000,143(6):1183-92.

[5] Tolkki L, Hokynar K, Meri S, et al. Granuloma annulare and morphea: Correlation with Borrelia burgdorferi infections and Chlamydia-related bacteria. Acta Derm Venereol, 2018,98(3):355-60.

[6] Farrell AM, Marren PM, Wojnarowska F. Genital lichen sclerosus associated with morphoea or systemic sclerosis: clinical and HLA characteristics. Br J Dermatol, 2000, 143(3):598-603.

[7] Desbois AC, Cacoub P. Systemic sclerosis: An update in 2016. Autoimmun Rev, 2016,15(5):417-26.

[8] Saracino AM, Denton CP, Orteu CH. The molecular pathogenesis of morphoeaMorphea: from genetics to future treatment targets. Br J Dermatol, 2017,177(1):3446.

[9] Wang Z, Wang Z, Lu Q. Epigenetic alterations in cellular immunity: new insights into autoimmune diseases. Cell Physiol Biochem, 2017,41(2):645-60.

[10] Aslani S, Sobhani S, Gharibdoost F, et al. Epigenetics and pathogenesis of systemic sclerosis; the ins and outs. Hum Immunol, 2018,79(3):178-87.

[11] Arnett FC, Gourh P, Shete S, et al. Major histocompatibility complex (MHC) class II alleles, haplotypes and epitopes which confer susceptibility or protection in systemic sclerosis: analyses in 1300 Caucasian, AfricanAmerican and Hispanic cases and 1000 controls. Ann
Rheum Dis, 2010,69(5):822-7.

[12] Simeon CP, Fonollosa V, Tolosa C, et al. Association of HLA class II genes with systemic sclerosis in Spanish patients. J Rheumatol, 2009,36(12):2733-6.

[13] Lothrenoo W, Kasitanon N, Wichainun R, et al. Association of HLA-DRB1*15:02 and DRB5*01:02 allele with the susceptibility to systemic sclerosis in THAI patients. Rhematol Int, 2013,33(8):2069-77.

[14] Tikly M, Rands A, McHugh N, et al. Human leukocyte antigen class II associations with systemic sclerosis in South Africans. Tissue Antigens, 2004,63(5):487-90.

[15] Rodriguez-Reyna TS, Mercado-Velázquez P, Yu N, et al. HLA class I and II blocks are associated to susceptibility, clinical subtypes and autoantibodies in Mexican systemic sclerosis (SSc) patients. PLoS One, 2015,10(5): e0126727.

[16] Salzano FM. Molecular variability in Amerindians: widespread but uneven information. An Acad Bras Cienc, 2002,74(2):223-63.

[17] Barquera R, Zuñiga J, Hernandez-Diaz R, et al. HLA class I and class II haplotypes in admixed families from several regions of Mexico. Mol Immunol, 2008,45(4):1171-8.

[18] Rubi-Castellanos R, Anaya-Palafox M, Mena-Rojas E, et al. Genetic data of 15 autosomal STRs (identifiler kit) of three Mexican Mestizo population samples from the states of Jalisco (west), Puebla (Center), and Yucatan 
(Southeast). Forensic Sci Int Genet, 2009,3(3):e71-6.

[19] Miller SA, Dykes DD, Polesky HF. A simple salting out procedure for extracting DNA from human nucleated cells. Nucleic Acids Res, 1988,16(3): 1215.

[20] Yamamoto-Furusho JK, Uscanga LF, Vargas-Alarcon $\mathrm{G}$, et al. Polymorphisms in the promoter region of tumor necrosis factor alpha (TNF-alpha) and the HLA-DRB1 locus in Mexican mestizo patients with ulcerative colitis. Immunol Lett, 2004,95(1):31-5.

[21] Fett NM. Morphea (localized scleroderma). JAMA Dermatol, 2013,149(9):1124.

[22] Fett N, Werth VP. Update on morphea. Part I Epidemiology, clinical presentation and pathogenesis. J Am Acad Dermatol, 2011,64(2):217-28.

[23] Jacobe H, Ahn C, Arnett FC, et al. Major histocompatibility complex class I and class II alleles may confer susceptibility to or protection against morphea: findings from the morphea in adults and children cohort. Arthritis Rheumatol, 2014,66(11):3170-7.

[24] Dryomov S, Nazhmidenova A, Shalaurova S, et al. Mitochondrial genome diversity at the Bering Strait area highlights prehistoric human migrations from $\mathrm{Si}-$ beria to northern North America. Eur J Hum Genet, 2015,23(10):1399-404.

[25] Ambrose SH. Late Pleistocene human population bottlenecks, volcanic winter and differentiation of modern humans. J Hum Evolut, 1998,34(6):623-51.

[26] Taboada N, Lardoeyt R. Genetic bottlenecks effect in American indigenous populations. Rev Inv Inf Salud(in Spanish), 2015,10(25):1-26.

[27] De Leo C, Castelán N, López M, et al. HLA class I and class II alleles and haplotypes in Mexican Mestizo established from serological typing of 50 families. Hum Biol, 1997,69(6):809-18.

[28] Vargas-Alarcón G, Gamboa R, Zuñiga J, et al. HLADR4 Allele frequencies on Indian and Mestizo population from Mexico. Hum Immmunol, 2000,61(3):341-4.

[29] Kashem SW, Correl CK, Vehe RK, et al. Inflammatory arthritis in pediatric patients with morphea. J Am Acad Dermatol, 2018,79(1):47-51.

[30] Merlin E, Breton S, Fraitag S, et al. Fibrous arthropathy associated with morphea: A new cause of diffuse acquired joint contractures. Pediatrics, 2017,140(4):e20161899.

[31] Brad DD, Kang AH, Rosloniec EF. Immunopathogenesis of collagen arthritis. Springer Semin Immunopathol, 2003,25(1):3-18.

[32] Behrens M, Trejo T, Luthra H, et al. Mechanism by which HLA-DR4 regulates sex-bias of arthritis in humanized mice. J Autoimmun, 2010,35(1):1-9.

[33] Zuloaga-Salcedo S, Castillo-Vazquez M, Vega-Memije E, et al. Class I and class II major histocompatibility complex genes in Mexican patients with actinic prurigo. Br J Dermatol, 2007,156(5):1074-5.

[34] Suárez A, Valbuena MC, Rey M, et al. Association of HLA subtype DRB1*0407 in Colombian patients with actinic prurigo. Photodermatol Photoimmunol Photomed, 2006,22(2):55-8.

[35] Rangel-Gamboa L, Vega-Memije ME, Acuña-Alonzo $\mathrm{V}$, et al. HLA class II in Mexican patients with pemphigus vulgaris: shared epitope for autoimmunity. Gac Med Mex, 2016,152(5):587-91.

[36] Branchet MC, Boisnic S, Blétry O, et al. Expression of HLA class II antigens on skin fibroblast in scleroderma. Br J Dermatol, 1992,126(5):431-5.

[37] Higley H, Persischitte K, Chu S, et al. Immunocytochemical localization and serologic detection of transforming growth factor $\beta 1$. Association with type 1 procollagen and inflammatory cell markers in diffuse and limited systemic sclerosis, morphoeaMorphea, and Raynaud's phenomenon. Arthritis Rheuma, 1994,37(2):278-88.

[38] Kowalczyk MJ, Dancak-Pazdrowska A, Szramka-Pawlak B, et al. Human endogenous retroviruses and chosen disease parameters in morphea. Postepy Dermatol Alergol, 2017,34(1):47-51.

[39] Chairta P, Nicolaou P, Christodoulou K. Genomic and genetic studies of systemic sclerosis: A systemic review. Hum Immunol, 2017,78(2):153-65.

[40] Kilinc F, Sener S, Akbas A, et al. Oxidative stress parameters in localized scleroderma patients. Arch Dermatol Res, 2016,308(9):625-9.

(Received 01 August 2018, Revised 04 September 2018, Accepted 07 September 2018) 